\title{
Similarity analysis of MHD flow field and heat transfer of a second grade convection flow over an unsteady stretching sheet
}

\author{
Rehan Ali Shah', Sajid Rehman ${ }^{2 *}$, M Idrees², M Ullah² and Tariq Abbas ${ }^{3}$
}

${ }^{*}$ Correspondence:
sajidrehman75@gmail.com
2Department of Mathematics,
Islamia College, Peshawar, Khyber
Pakhtoon Khwa, Pakistan
Full list of author information is
available at the end of the article

\begin{abstract}
Unsteady magnetohydrodynamic (MHD) flow of a second grade fluid over a stretching sheet is a focus of this steady. Surface tension is considered to be varies linearly with temperature. The stretching velocity is defined in (Liu and Andersson in Int. J. Therm. Sci. 47(6):766-772, 2008). Similarity transformation reported by Abbas et al. (Math. Comput. Model. 48:518-526, 2008) are used to develop nonlinear system of differential equations coupled in velocity and temperature fields. The system is solved by the homotopy-analysis method (HAM), while the effects of different parameters such as the unsteadiness parameter $\mathrm{S}$, film thickness, Hartmann number $\mathrm{Ma}$, PrandtI number Pr, Thermocapillary number $M$, heat flux $-\theta^{\prime}(0)$, surface skin-friction coefficient $f^{\prime \prime}(0)$, free surface temperature $\theta(1)$ for flow field, and heat transfer are studied in this article.
\end{abstract}

Keywords: second grade fluid; HAM; magnetic field; thin film; free surface flow; unsteady stretching surface; similarity transformations; Grashof number; thermocapillary number

\section{Introduction}

In many manufacturing processes the flows of non-Newtonian fluids have acquired special attention because boundary layer behavior over the flow and heat transfer phenomena of an unsteady two-dimensional free surface flow of a viscous incompressible conducting fluid have promising applications, such as the performance of lubricants, metal and polymer extrusion, application of paints, drawing of plastic sheets, fiber and wire coating, transpiration cooling, foodstuff processing and movement of biological fluids, chemical equipments, reactor fluidization and microchip production, continuous casting, and the process of designing various heat exchangers. The rate of heat transfer of the stretching sheet determines the best quality product for the coating process. Much research has been carried out on the non-Newtonian boundary layer equations in Cartesian coordinates both theoretically and experimentally. However, the non-Newtonian fluids cannot be described simply like Newtonian fluids. Therefore several researchees proposed their respective models for non-Newtonian fluids. Among these, viscoelastic fluids have a high status for the researchers due to its special characteristics. The simplest subclass of viscoelastic fluids is the second grade fluid, for which an analytic solution is possible.

(c) The Author(s) 2017. This article is distributed under the terms of the Creative Commons Attribution 4.0 International License (http://creativecommons.org/licenses/by/4.0/), which permits unrestricted use, distribution, and reproduction in any medium, provided you give appropriate credit to the original author(s) and the source, provide a link to the Creative Commons license, and indicate if changes were made. 
Sakiadis [3, 4] in 1961 was first to present various aspects on boundary layer behavior on continuous solid surface of the stretching problem involving Newtonian and nonNewtonian fluids; these have been extensively studied by several authors. Crane [5] in 1970 was first to study the hydrodynamics of a steady stretching of a flat elastic sheet in a two-dimensional boundary layer flow by reducing the steady Navier-Stokes equations to a nonlinear ordinary differential equations by means of a similarity transformation. Wang [6] in 1990 first studied the hydrodynamics of an unsteady stretching surface in a thin liquid film of a flow by converting the unsteady Navier-Stokes equations to a nonlinear ordinary differential equations by means of a similarity transformation. But Lai and Kulacki [7], in 1991, assumed that viscosity and thermal conductivity vary as inverse functions of the temperature and then solved the equations numerically by using the Runge-Kutta shooting method. Anderson et al. [8] in 2000 extended the work of Wang [6] by studying heat transfer and an analysis has been performed by shooting method. Liao [9] in 2004 was first to introduce the homotopy-analysis method (HAM). The problem studied by Anderson et al. [8] was considered by Wang [10] in 2006, he presented an analytical solution using HAM [9] and found good agreement with that of the multiple shooting method. Wang et al. [11] in 2006 presented HAM solutions for the non-Newtonian problem studied by Anderson et al. [12]. Furthermore, in 2007 thermocapillary effects were discussed by Dandapat et al. [13] and Chen [14], and viscous dissipation in the presence of a magnetical effect was discussed by Abel et al. [15] in 2008. A more extended form considered by Liu et al. [1] in 2008 for the stretching sheet of the prescribed temperature variation was considered by Anderson et al. [8]. Noor et al. [16] in 2010 introduced a magnetic field as considered in [15] and thermocapillary effect as used in [13] to extend the model in [1]. Further Noor et al. [16] in 2010 took a similarity transformation from [10, 11] and used it for the purpose of reducing the range of independent variables to 0-1. A more realistic approach was used by Yasir et al. [17] in 2011 by studying the flow over a stretching sheet by taking variable physical properties. For solution purposes they used the homotopyperturbation method (HPM). Hazarika and Konch [18] in 2014 investigated the effects of varying thermal conductivity and viscosity, variable heat flux and constant suction on the magnetic hydrodynamics (MHD) boundary layer flow forced by convection past a stretching/shrinking sheet.

Similarly Hayat et al. [19] in 2007 considered a steady second grade fluid. Magnetic field is applied normal to the flow of electrically conducted fluid in a porous channel while solution is possible by using HAM. Abbas et al. [2] in 2008 investigated the flow of an unsteady second grade fluid over a stretching surface, where HAM gives the analytical solution for the model problem. Meanwhile Abel and Mahesha [20] in 2008 studied the MHD boundary layer flow of a non-Newtonian viscoelastic fluid in the presence of non-uniform heat source and thermal radiation. Moreover, the thermal conductivity may vary linearly with temperature and the regular perturbation technique is used for solution. Further Hayat $e t$ al. [21] in 2011 used convective boundary conditions for the second grade fluid and HAM has been used for the series result. Hussnain et al. [22] in 2012 used HAM for the analytic solution of second grade fluid in the rotating system between two horizontal plates in the presence of a transverse magnetic field. Recently Temitope and Samuel [23] in 2015 worked out on the variable physical properties in the steady second grade fluid, solution is establish by numerical Runge-Kutta shooting technique. Meanwhile Gital et al. [24] in 2015 proposed a problem of unsteady second grade fluid due to an oscillating porous wall 
and modified version of the variable separation technique is used for the solution. Very recently Das and Sharma [25] in 2016 investigated a second grade MHD fluid past a semiinfinite stretching sheet which is electrically conducting, while there is convective surface heat flux along them. Furthermore, the influence of MHD on the fluid flow in various geometries was studied in [26-32].

Motivated by these analyses, the aim of the present investigation is to observe the case of a non-Newtonian fluid for thin film two-dimensional flow satisfying the constitutive equations of second grade fluid with heat transfer over an unsteady stretching sheet under the influence of a transverse magnetic field with surface tension in the boundary conditions. The surface tension varies linearly with temperature. The model boundary layer non-linear partial differential equations transform to ODEs by means of proper transformations concerning the geometry of the problem under consideration. Analyses are made for skin friction, heat transfer and for the flow speed's various natural parameters by using the well-known analytical method HAM. Different effects of non-dimensional values such as unsteadiness parameter, film thickness, Hartmann number, surface skin-friction coefficient, Prandtl number, Thermocapillary number, heat flux, and free surface temperature are discussed and sketched for the effects of various pertinent parameters and meaningful results have been pointed out.

\section{Problem formulation}

\subsection{Governing equations}

Consider a thin elastic sheet of uniform thickness $h(t)$ of a second grade fluid which is due to incompressible, unsteady and two-dimensional flow that emerges from a narrow slit at the origin of the Cartesian coordinate system. The horizontal axis ( $x$-axis) is considered to be along the stretching sheet, while the magnetic field $B=B_{0} /(1-\alpha t)^{1 / 2}$ is vertical to the stretching sheet is applied along the direction of gravity, which is located along the $y$-axis. An infinite horizontal disk is placed at $z=0$ in a viscous incompressible non-Newtonian fluid. For the Cauchy stress tensor in a second grade fluid one is referred to [33, 34], whose data is experimentally fit with polymer melts given in [34] and is given as

$$
T=-p I+\mu A_{1}+\alpha_{1} A_{2}+\alpha_{2} A_{1}^{2}
$$

where $p$ represents pressure, $I$ is the identity tensor, $\mu$ is the viscosity, $\alpha_{i}(i=1,2)$ the material constants and $A_{1}, A_{2}$ are Rivlin-Ericksen tensors, which can be further defined as

$$
\begin{aligned}
& A_{1}=(\operatorname{grad} V)+(\operatorname{grad} V)^{t}, \\
& A_{2}=\frac{d A_{1}}{d t}+A_{1}(\operatorname{grad} V)+(\operatorname{grad} V)^{t} A_{1},
\end{aligned}
$$

here $d / d t$ represents the material time derivative and $V$ is the velocity. By assumption, the Clausius-Duhem inequality is satisfied and the minimum Helmholtz free energy is taken when the fluid is locally at rest and we have

$$
\mu \geq 0, \quad \alpha_{1} \geq 0, \quad \alpha_{1}+\alpha_{2}=0
$$

when $\alpha_{1}=\alpha_{2}=0$; the second grade fluid reduces to that of a viscous fluid. Employing the above expressions, the momentum and energy equations governing the unsteady incom- 
pressible flow of a second grade fluid are $[2,21,26]$

$$
\begin{aligned}
\frac{\partial u}{\partial x}+ & \frac{\partial v}{\partial y}=0 \\
\frac{\partial u}{\partial t}+ & u \frac{\partial u}{\partial x}+v \frac{\partial u}{\partial y} \\
= & v\left(2 \frac{\partial^{2} u}{\partial x^{2}}+\frac{\partial^{2} u}{\partial y^{2}}+\frac{\partial^{2} v}{\partial x \partial y}\right) \\
& +\frac{\alpha_{1}}{\rho}\left[2 \frac{\partial^{3} u}{\partial t \partial x^{2}}+\frac{\partial^{3} u}{\partial t \partial y^{2}}+\frac{\partial^{3} v}{\partial t \partial x \partial y}+2 \frac{\partial u}{\partial x} \frac{\partial^{2} u}{\partial x^{2}}+2 u \frac{\partial^{3} u}{\partial x^{3}}+2 v \frac{\partial^{3} u}{\partial x^{2} \partial y}\right. \\
& +2 \frac{\partial v}{\partial x} \frac{\partial^{2} v}{\partial x^{2}}+u \frac{\partial^{3} u}{\partial x \partial y^{2}}+u \frac{\partial^{3} v}{\partial x^{2} \partial y}+v \frac{\partial^{3} u}{\partial y^{3}} \\
& \left.+v \frac{\partial^{3} v}{\partial x \partial y^{2}}+\frac{\partial u}{\partial y} \frac{\partial^{2} v}{\partial x^{2}}+2 \frac{\partial v}{\partial y} \frac{\partial^{2} v}{\partial x \partial y}-\frac{\partial u}{\partial y} \frac{\partial^{2} v}{\partial y^{2}}+\frac{\partial u}{\partial x} \frac{\partial^{2} u}{\partial y^{2}}-\frac{\partial u}{\partial x} \frac{\partial^{2} v}{\partial x \partial y}\right] \\
& +\frac{g B(T-T 0)}{\rho}-\frac{\hat{\sigma} B^{2}}{\rho} u, \\
\frac{\partial v}{\partial t}+ & u \frac{\partial v}{\partial x}+v \frac{\partial v}{\partial y} \\
= & v\left(\frac{\partial^{2} u}{\partial x \partial y}+\frac{\partial^{2} v}{\partial x^{2}}+2 \frac{\partial^{2} v}{\partial y^{2}}\right) \\
& +\frac{\alpha_{1}}{\rho}\left[\frac{\partial^{3} u}{\partial t \partial x \partial y}+\frac{\partial^{3} v}{\partial t \partial x^{2}}+2 \frac{\partial^{3} v}{\partial t \partial y^{2}}+2 \frac{\partial u}{\partial x} \frac{\partial^{2} u}{\partial x \partial y}+u \frac{\partial^{3} u}{\partial x^{2} \partial y}+u \frac{\partial^{3} v}{\partial x^{3}}+v \frac{\partial^{3} u}{\partial x \partial y^{2}}\right. \\
& +v \frac{\partial^{3} v}{\partial x^{2} \partial y}+\frac{\partial v}{\partial x} \frac{\partial^{2} u}{\partial y^{2}} \\
& \left.-\frac{\partial v}{\partial x} \frac{\partial^{2} u}{\partial x^{2}}-\frac{\partial v}{\partial y} \frac{\partial^{2} u}{\partial x \partial y}+\frac{\partial v}{\partial y} \frac{\partial^{2} v}{\partial x^{2}}+2 u \frac{\partial^{3} v}{\partial x \partial y^{2}}+2 \frac{\partial v}{\partial y} \frac{\partial^{2} v}{\partial y^{2}}+2 v \frac{\partial^{3} v}{\partial y^{3}}+2 \frac{\partial u}{\partial y} \frac{\partial^{2} u}{\partial y^{2}}\right] \\
+ & \frac{\partial T}{\partial x}+v \frac{\partial T}{\partial y}=\kappa\left(\frac{\partial^{2} T}{\partial x^{2}}+\frac{\partial^{2} T}{\partial y^{2}}\right) . \\
&
\end{aligned}
$$

The following scaling is used for the governing equations with boundary conditions to transform into their dimensionless form:

$$
\begin{aligned}
& x=L x^{*}, \quad y=\hat{\delta} y^{*}, \quad u=U u^{*}, \quad v=\frac{U \hat{\delta}}{L} v^{*}, \\
& t=\frac{L}{U} t^{*}, \quad g=\frac{U^{2}}{L} g^{*}, \quad T=T^{*}\left(T_{s}-T_{0}\right)+T_{0},
\end{aligned}
$$

where $\hat{\delta}$ and $L$ are the length scales in the vertical and horizontal directions, respectively, $\frac{\hat{\delta}}{L} \ll 1$ is the aspect ratio, $T_{0}$ the temperature of fluid at the surface of the stretching sheet and $T_{s}$ is temperature of fluid at the surface. By using the above non-dimensional variables and removing the asterisk this becomes

$$
\frac{\partial u}{\partial x}+\frac{\partial v}{\partial y}=0
$$




$$
\begin{aligned}
\frac{\partial u}{\partial t}+u \frac{\partial u}{\partial x}+v \frac{\partial u}{\partial y}= & v \frac{\partial^{2} u}{\partial y^{2}}+\frac{\alpha_{1}}{\rho}\left[\frac{\partial^{3} u}{\partial t \partial y^{2}}+u \frac{\partial^{3} u}{\partial x \partial y^{2}}+v \frac{\partial^{3} u}{\partial y^{3}}-\frac{\partial u}{\partial y} \frac{\partial^{2} v}{\partial y^{2}}+\frac{\partial u}{\partial x} \frac{\partial^{2} u}{\partial y^{2}}\right] \\
& +\frac{g ß\left(T_{s}-T_{0}\right) \theta}{\rho}-\frac{L \hat{\sigma} B^{2}}{U \rho} u, \\
\frac{\partial T}{\partial t}+u \frac{\partial T}{\partial x}+v \frac{\partial T}{\partial y}= & \kappa \frac{\partial^{2} T}{\partial y^{2}},
\end{aligned}
$$

subject to boundary conditions [1]

$$
\begin{aligned}
& u=U_{s}, \quad v=0, \quad T=T_{s} \quad \text { at } y=0, \\
& \mu \frac{\partial u}{\partial y}=\frac{\partial \sigma}{\partial x}, \quad v=\frac{d h}{d t}, \quad \frac{\partial T}{\partial y}=0 \quad \text { at } y=h,
\end{aligned}
$$

where $u$ and $v$ are in the $x$ and $y$ direction components of the velocity of the fluid, $T$ is the temperature, $\hat{\sigma}$ the electrical conductivity, $t$ the time, $v$ the kinematic viscosity, $\rho$ the density, $\mu$ the viscosity, $\kappa$ the thermal diffusivity, and $\sigma$ is the surface tension, which varies linearly with temperature,

$$
\sigma=\sigma_{0}\left[1-\frac{\delta x(1-\alpha t)^{\frac{1}{2}}}{2 v b}\left(T-T_{0}\right)\right],
$$

$\delta$ represents a positive fluid characteristic. The surface stretching velocity is defined in [1] as

$$
U_{s}=b x(1-\alpha t)^{-1}
$$

where $\alpha$ and $b$ are both positive constants. The initial stretching rate is denoted by $b$, $b /(1-\alpha t)$ is the effective stretching rate. It is assumed that the surface is smooth and there is no wave at the surface of the liquid film. As taken by Liu et al. [1], for having a uniform film thickness the stretching surface velocity will be (12), i.e. it does not depend on position. The surface temperature of the stretching sheet is chosen to be dependent on both time and location along the sheet as

$$
T_{s}=T_{0}-T_{\text {ref }} \frac{b^{2} x}{(1-\alpha t)^{2}},
$$

since $T_{0}$ is the stretching sheet temperature and $T_{\text {ref }}$ is the reference temperature (constant) for all $t<1 / \alpha$.

\subsection{Similarity transformation}

We will be making use of the surface velocity given in (12) and surface temperature (13) combined with the similarity transformations in equations (7) and (8) given as [1]

$$
\begin{aligned}
& u=\frac{b x}{1-\alpha t} f^{\prime}(\eta), \\
& v=-\frac{(\nu b)^{\frac{1}{2}}}{(1-\alpha t)^{\frac{1}{2}}} \beta f(\eta),
\end{aligned}
$$


where $u$ and $v$ are the velocity components along $x$ - and $y$-axis, respectively. Furthermore, the temperature is defined as

$$
T=T_{0}-T_{\text {ref }} b^{2} x(1-\alpha t)^{-2} \theta(\eta),
$$

where in [1] the similarity variable $\eta$ is

$$
\eta=\left(\frac{b}{v}\right)^{\frac{1}{2}}(1-\alpha t)^{\frac{-1}{2}} \beta^{-1} y
$$

the unknown $\beta$ is a constant representing the dimensionless film thickness, taken from $[1]$,

$$
\beta=\left(\frac{b}{v}\right)^{\frac{1}{2}}(1-\alpha t)^{\frac{-1}{2}} h(t),
$$

equations (6)-(10) are transformed to the following non-linear system of coupled equations:

$$
\begin{aligned}
f^{\prime \prime \prime} & +K\left[2 S f^{\prime \prime \prime}+\frac{1}{2} S \eta f^{\prime \prime \prime \prime}+2 f^{\prime} f^{\prime \prime \prime}-f^{\prime \prime \prime \prime}+f^{\prime \prime 2}\right] \\
& -\Upsilon\left[\frac{1}{2} S \eta f^{\prime \prime}+f^{\prime 2}-f^{\prime \prime}+G r \theta+(S+M a) f^{\prime}\right]=0, \\
\theta^{\prime \prime} & +\operatorname{Pr} \Upsilon\left[f \theta^{\prime}-f^{\prime} \theta-2 S \theta-\frac{S}{2} \eta \theta^{\prime}\right]=0 .
\end{aligned}
$$

The physically valid boundary conditions for the modeled problem are

$$
\begin{aligned}
& f(0)=0, \quad f^{\prime}(0)=1, \quad \theta(0)=1, \\
& f(1)=\frac{1}{2} S, \quad f^{\prime \prime}(1)=M \theta(1), \quad \theta^{\prime}(1)=0,
\end{aligned}
$$

where a prime used for differentiation with respect to $\eta, K=\alpha_{1} \frac{b(1-\alpha t)^{-1}}{\rho v}$ is the dimensionless second grade parameter (viscoelastic parameter), $G r=g \beta T_{\text {ref }}$ is the Grashof number, $S=\alpha / b$ is the non-dimensional parameter of unsteadiness, $M a=L \hat{\sigma}, B_{0}^{2} / U \rho b$ the Hartmann number, $\Upsilon=\beta^{2}$ is the non-dimensional film thickness, $P r=v / k$ the Prandtl number, and $M$ is the thermocapillary number defined by $M=\frac{\delta \sigma_{0} T_{\text {ref }} \beta}{\mu \sqrt{b v}}$.

\section{Problem approach}

\subsection{Skin-friction coefficient and Nusselt number}

The physical quantities of interest are skin-friction coefficient and local Nusselt number. The shear stress $\tau_{w}$ on the surface of the thin liquid film sheet is

$$
\tau_{w}=\left[\mu \frac{\partial u}{\partial y}+\alpha_{1}\left(\frac{\partial^{2} u}{\partial t \partial y}+u \frac{\partial^{2} u}{\partial x \partial y}+v \frac{\partial^{2} u}{\partial y^{2}}-\frac{\partial u}{\partial y} \frac{\partial v}{\partial y}+\frac{\partial u}{\partial x} \frac{\partial u}{\partial y}\right)\right]_{y=0},
$$

and the local skin-friction coefficient or frictional drag coefficient is

$$
C_{f}=\frac{\tau_{w}}{\rho U^{2}} .
$$


In dimensionless form we have

$$
\operatorname{Re}_{x}^{1 / 2} C_{f}=\frac{1}{\beta}\left[f^{\prime \prime}(\eta)+K\left(\frac{3}{2} S f^{\prime \prime}(\eta)+\frac{1}{2} S \eta f^{\prime \prime \prime}(\eta)-f(\eta) f^{\prime \prime \prime}(\eta)+3 f^{\prime}(\eta) f^{\prime \prime}(\eta)\right)\right]_{\eta=0},
$$

where $R e_{x}^{1 / 2}=b x^{2} / \nu(1-\alpha t)$ is the local Reynolds number. The heat transfer from the sheet $q_{w}$ is given by $q_{w}=-\kappa\left(\frac{\partial T}{\partial y}\right)_{y=0}$ and the Nusselt number is $N u_{x}=\frac{x q_{w}}{\kappa\left(T_{0}-T_{s}\right)}$, with $\kappa$ and $\mu$ being thermal conductivity and the dynamic viscosity, respectively. So the general form of the rate of heat transfer [6] and the skin friction for the thin liquid film are given by

$$
R e_{x}^{-1 / 2} N u_{x} \equiv\left[\frac{1}{\beta} \theta^{\prime}(\eta)\right]_{\eta=0}
$$

\subsection{Solution approach}

The model given in equations (19)-(22), are solved by the homotopy-analysis method (HAM) $[9,35]$. HAM is a semi-analytical technique to solve nonlinear ordinary/partial differential equations. The homotopy-analysis method entails the concept of homotopy from topology to develop a convergent series solution for nonlinear systems. This is implemented by applying a homotopy-Maclaurin series to compromise with the nonlinearities in the system. It is a series development method that is not precisely dependent on small or large natural parameters. Thus, it is suitable for not only weakly but also strongly nonlinear models, addressing some of the fundamental conditions of the basic perturbation methods. Further, the HAM is a cooperative method for the delta expansion method, the Lyapunov artificial small parameter method, the homotopy perturbation method and the Adomian decomposition method. The higher generalization of the method usually takes for granted the strong convergence of the solution over larger spatial and parameter domains. Furthermore, the HAM gives excellent flexibility in the expression of the solution and how the solution is explicitly obtained. It provides great freedom to choose the basis functions of the desired solution and the corresponding auxiliary linear operator of the homotopy. Finally, unlike the other analytic approximation techniques, HAM provides a simple way to ensure the convergence of the solution series. Free software based on the homotopy-analysis method for nonlinear boundary-value and eigenvalue problems is available called Mathematica package BVPh2.0.

The functions $f(\eta)$ and $\theta(\eta)$ can be written in terms of $\left\{\eta^{m} \mid m=0,1,2, \ldots\right\}$ as

$$
\begin{aligned}
& f(\eta)=\sum_{m=0}^{+\infty} a_{m} \eta^{m}, \\
& \theta(\eta)=\sum_{m=0}^{+\infty} c_{m} \eta^{m},
\end{aligned}
$$

where $a_{m}$ and $c_{m}$ are the constants. The initial guesses for the corresponding $f(\eta)$ and $\theta(\eta)$ satisfying the given boundary conditions (21) and (22) are

$$
\begin{aligned}
& f_{0}(\eta)=\eta+\frac{3 S-6-M \theta_{0}(\eta)}{4} \eta^{2}+\frac{2-S+M \theta_{0}(\eta)}{4} \eta^{3}, \\
& \theta_{0}(\eta)=1,
\end{aligned}
$$


where the auxiliary linear operators for equations (27) and (28) are $£_{f}=\partial^{4} / \partial \eta^{4}$ and $£_{\theta}=$ $\partial^{2} / \partial \eta^{2}$, respectively, with the characteristics

$$
\begin{aligned}
& £_{f}\left[C_{1}+C_{2} \eta+C_{3} \eta^{2}+C_{4} \eta^{3}\right]=0, \\
& £_{\theta}\left[C_{1}+C_{2} \eta\right]=0,
\end{aligned}
$$

the integration constants are denoted by $C_{1}, C_{2}, C_{3}$ and $C_{4}$. The non-linear operators are constructed from equations (19) and (20) as

$$
\begin{aligned}
\aleph_{f}[F(\eta ; q), \Theta(\eta ; q), \Gamma(q)]= & F^{\prime \prime \prime}+K\left[2 S F^{\prime \prime \prime}+\frac{1}{2} S \eta F^{\prime \prime \prime \prime}+2 F^{\prime} F^{\prime \prime \prime}-F F^{\prime \prime \prime \prime}+F^{\prime \prime 2}\right] \\
& -\Gamma\left[\frac{1}{2} S \eta F^{\prime \prime}+F^{\prime 2}-F F^{\prime \prime}+G r \Theta+(S+M a) F^{\prime}\right], \\
\aleph_{\theta}[F(\eta ; q), \Theta(\eta ; q), \Gamma(q)]= & \Theta^{\prime \prime}+\operatorname{Pr} \Gamma\left[F \Theta^{\prime}-F^{\prime} \Theta-\frac{1}{2} S \eta \Theta^{\prime}-2 S \Theta\right],
\end{aligned}
$$

where the unknown functions $F(\eta ; q)$ and $\Theta(\eta ; q)$ depends upon $\eta$ and $q$, and the function $\Gamma$ depends only on $q$. A prime in the superscript indicates the number of derivatives with respect to $\eta$. Here the auxiliary parameters are $\hbar_{f} \neq 0$ and $\hbar_{\theta} \neq 0$, while the non-zero auxiliary functions are represented by $H_{f}$ and $H_{\theta}$. The deformation equation for zeroth order can be expressed as

$$
\begin{aligned}
& (1-q) £_{f}\left[F(\eta, q)-f_{0}(\eta)\right]=q \hbar_{f} H_{f} \aleph_{f}[F(\eta, q), \Theta(\eta, q), \Gamma(q)] \\
& (1-q) £_{\theta}\left[\Theta(\eta, q)-\theta_{0}(\eta)\right]=q \hbar_{\theta} H_{\theta} \aleph_{\theta}[F(\eta, q), \Theta(\eta, q), \Gamma(q)]
\end{aligned}
$$

the boundary conditions are

$$
\begin{aligned}
& F(0 ; q)=0, \quad F^{\prime}(0 ; q)=1, \quad \Theta(0 ; q)=1, \quad F(1 ; q)=\frac{1}{2} S, \\
& F^{\prime \prime}(1 ; q)=M \Theta(1 ; q), \quad \Theta^{\prime}(1 ; q)=0,
\end{aligned}
$$

the embedding parameter is $0 \leq q \leq 1$. From equations (35) and (36), it is observed that, when $q=0$, this implies that equations (27) and (28) are obtained as

$$
F(\eta ; 0)=f_{0}(\eta), \quad \Theta(\eta ; 0)=\theta_{0}(\eta)
$$

As $q=1$ and $\hbar_{f}, \hbar_{\theta} \neq 0$ and $H_{f}, H_{\theta} \neq 0$, equations (33)-(35) give equations (19)-(22), respectively, but

$$
F(\eta ; 1)=f(\eta), \quad \Theta(\eta ; 1)=\theta(\eta), \quad \Gamma(1)=\Upsilon .
$$

On increasing $q$ from zero to one, the approximate solutions $F(\eta ; q)$ and $\Theta(\eta ; q)$ converge to exact solutions $f(\eta)$ and $\theta(\eta)$, respectively;

$$
\Gamma(0)=\Upsilon_{0},
$$


the initial guess for the time-scale parameter $\Upsilon$. By using a Maclaurin series combining with (27) and (28), the functions $F(\eta ; q), \Theta(\eta ; q)$ and $\Gamma(q)$ can be expanded as a series of $q$ as

$$
\begin{aligned}
& F(\eta ; q)=f_{0}(\eta)+\sum_{m=1}^{+\infty} f_{m}(\eta) q^{m}, \\
& \Theta(\eta ; q)=\theta_{0}(\eta)+\sum_{m=1}^{+\infty} \theta_{m}(\eta) q^{m}, \\
& \Gamma(q)=\Upsilon_{0}+\sum_{m=1}^{+\infty} \Upsilon_{m} q^{m},
\end{aligned}
$$

where

$$
\begin{aligned}
& f_{m}(\eta)=\frac{1}{m !}\left[\frac{\partial^{m} F(\eta ; q)}{\partial q^{m}}\right]_{q=0}, \\
& \theta_{m}(\eta)=\frac{1}{m !}\left[\frac{\partial^{m} \Theta(\eta ; q)}{\partial q^{m}}\right]_{q=0}, \\
& \Upsilon_{m}=\frac{1}{m !}\left[\frac{\partial^{m} \Gamma(q)}{\partial q^{m}}\right]_{q=0},
\end{aligned}
$$

using (37) we have

$$
\begin{aligned}
& f(\eta)=f_{0}(\eta)+\sum_{m=1}^{+\infty} f_{m}(\eta), \\
& \theta(\eta)=\theta_{0}(\eta)+\sum_{m=1}^{+\infty} \theta_{m}(\eta), \\
& \Upsilon=\Upsilon_{0}+\sum_{m=1}^{+\infty} \Upsilon_{m} .
\end{aligned}
$$

Differentiating $m$ times equations (33) and (34) with respect to $q$ after putting $q=0$ and dividing both sides by $m$ !, we finally get the $m$ th-order deformation equations

$$
\begin{aligned}
& £_{f}\left[f_{m}(\eta)-\chi_{m} f_{m-1}(\eta)\right]=\hbar_{f} H_{f}(\eta) R_{f, m}(\eta), \\
& £_{\theta}\left[\theta_{m}(\eta)-\chi_{m} \theta_{m-1}(\eta)\right]=\hbar_{\theta} H_{\theta}(\eta) R_{\theta, m}(\eta),
\end{aligned}
$$

with boundary conditions

$$
\begin{aligned}
& f_{m}(0)=0, \quad f_{m}^{\prime}(0)=0, \quad \theta_{m}(0)=0, \\
& f_{m}(1)=0, \quad f_{m}^{\prime \prime}(1)=M \theta_{m}(1), \quad \theta_{m}^{\prime}(1)=0,
\end{aligned}
$$

for $m \geq 1$

$$
R_{f, m}(\eta)=f_{m-1}^{\prime \prime \prime}+K\left[2 S f_{m-1}^{\prime \prime \prime}+\frac{1}{2} S \eta f_{m-1}^{\prime \prime \prime \prime}+2 \sum_{n=0}^{m-1}\left(f_{n}^{\prime} f_{m-1-n}^{\prime \prime \prime}-f_{n} f_{m-1-n}^{\prime \prime \prime \prime}+f_{n}^{\prime \prime} f_{m-1-n}^{\prime \prime}\right)\right]
$$




$$
\begin{aligned}
& -\sum_{n=0}^{m-1} \Upsilon_{n}\left[\frac{1}{2} S \eta f_{m-1-n}^{\prime \prime}+\sum_{i=0}^{n}\left(f_{i}^{\prime} f_{n-i}^{\prime}-f_{i} f_{n-i}^{\prime \prime}\right)+G r \theta_{m-1-n}\right. \\
& \left.+(S+M a) f_{m-1-n}^{\prime}\right], \\
R_{\theta, m}(\eta)= & \theta_{m-1}^{\prime \prime}+\operatorname{Pr} \sum_{n=0}^{m-1} \Upsilon_{n}\left[\sum_{i=0}^{n}\left(f_{i} \theta_{n-i}^{\prime}-f_{i}^{\prime} \theta_{n-i}\right)-2 S \theta_{m-1-n}-\frac{S}{2} \eta \theta_{m-1-n}^{\prime}\right],
\end{aligned}
$$

and

$$
\chi_{m}= \begin{cases}1, & m>1, \\ 0, & m=1,\end{cases}
$$

the solution of (48) and (49) can be expressed as

$$
\begin{aligned}
f_{m}(\eta)= & \int_{0}^{\eta} \int_{0}^{\eta} \int_{0}^{\eta} \int_{0}^{\eta} \hbar_{f} H_{f}(s) R_{f, m}(s) d s d s d s d s \\
& +\chi_{m} f_{m-1}+C_{1}+C_{2} \eta+C_{3} \eta^{2}+C_{4} \eta^{3}, \\
\theta_{m}(\eta)= & \int_{0}^{\eta} \int_{0}^{\eta} \hbar_{\theta} H_{\theta}(s) R_{\theta, m}(s) d s d s+\chi_{m} \theta_{m-1}+C_{1}+C_{2} \eta .
\end{aligned}
$$

Thus $m$ th-order approximation of $f(\eta), \theta(\eta)$ and $\Upsilon$ are expressed as

$$
\begin{aligned}
& f(\eta) \approx \sum_{n=0}^{m} f_{n}(\eta), \\
& \theta(\eta) \approx \sum_{n=0}^{m} \theta_{n}(\eta), \\
& \Upsilon \approx \sum_{n=0}^{m-1} \Upsilon_{n},
\end{aligned}
$$

by simultaneously solving equation $f_{n+1}(\eta)$ with the help of the boundary conditions $f_{n+1}(1)=0$ and $f_{n+1}^{\prime \prime}(1)=0$ mentioned in (51) $\forall n \geq 0$ to obtain $\Upsilon_{n}$.

\subsection{Optimal convergence control parameters}

First made error analysis and then giving theoretical observations. For investigation purposes Tables 1-3 are presented and Figures 1-5 are drawn. During the HAM solution a

Table 1 Optimal value of convergence control parameters versus different orders of approximation

\begin{tabular}{llllr}
\hline $\begin{array}{l}\text { Order of } \\
\text { approximation }\end{array}$ & $\hbar_{\boldsymbol{f}}$ & $\hbar_{\boldsymbol{\theta}}$ & $\boldsymbol{\varepsilon}_{\boldsymbol{m}}^{\boldsymbol{t}}$ & \multicolumn{1}{c}{ CPU time } \\
\hline 2 & -0.816110 & -0.570098 & $7.37847 \times 10^{-3}$ & 11.3260 seconds \\
3 & -0.830974 & -0.761688 & $1.30091 \times 10^{-4}$ & 18.5925 seconds \\
4 & -0.840993 & -0.617020 & $1.99436 \times 10^{-6}$ & 37.0145 seconds \\
5 & -0.846134 & -0.687839 & $3.39372 \times 10^{-8}$ & 63.8482 seconds \\
6 & -0.850443 & -0.690781 & $5.04199 \times 10^{-10}$ & 108.937 seconds \\
7 & -0.858637 & -0.731049 & $-1.1845 \times 10^{-10}$ & 196.690 seconds \\
\hline
\end{tabular}


Table 2 Individual averaged squared residual errors using optimal values of auxiliary parameters

\begin{tabular}{rllr}
\hline $\boldsymbol{m}$ & $\boldsymbol{\varepsilon}_{\boldsymbol{m}}^{\boldsymbol{f}}$ & $\boldsymbol{\varepsilon}_{\boldsymbol{m}}^{\boldsymbol{\theta}}$ & CPU time \\
\hline 2 & $2.54396 \times 10^{-3}$ & $2.50182 \times 10^{-7}$ & 2.46878 seconds \\
4 & $3.93474 \times 10^{-7}$ & $5.39818 \times 10^{-9}$ & 6.66087 seconds \\
6 & $1.08366 \times 10^{-10}$ & $1.16081 \times 10^{-10}$ & 13.5679 seconds \\
8 & $6.10692 \times 10^{-13}$ & $2.49521 \times 10^{-12}$ & 22.4765 seconds \\
10 & $2.17244 \times 10^{-14}$ & $5.36337 \times 10^{-14}$ & 34.5937 seconds \\
12 & $5.23527 \times 10^{-16}$ & $1.15284 \times 10^{-15}$ & 49.7814 seconds \\
14 & $1.14949 \times 10^{-17}$ & $2.47801 \times 10^{-17}$ & 67.1306 seconds \\
16 & $2.47258 \times 10^{-19}$ & $5.32646 \times 10^{-19}$ & 86.7832 seconds \\
18 & $5.26476 \times 10^{-21}$ & $1.14492 \times 10^{-20}$ & 110.962 seconds \\
20 & $1.00927 \times 10^{-22}$ & $2.46099 \times 10^{-22}$ & 138.456 seconds \\
\hline
\end{tabular}

Table 3 Convergence of HAM on the basis of skin friction $f^{\prime \prime}(0)$ and heat flux $-\theta^{\prime}(0)$ for selected values of $M a=1, M=1, \Upsilon=0.127013, P r=0.2, G r=5, S=0.2$ and $K=0.1$

\begin{tabular}{|c|c|c|}
\hline $\bar{m}$ & $f^{\prime \prime}(0)$ & $-\theta^{\prime}(0)$ \\
\hline 1 & -2.987594767874287 & 0.001666755677540 \\
\hline 5 & -2.988314378094173 & 0.002678333954988 \\
\hline 10 & -2.988310366379021 & 0.002700353358962 \\
\hline 15 & -2.988310346982944 & 0.002700534393216 \\
\hline 18 & -2.988310346828816 & 0.002700535809751 \\
\hline 20 & -2.988310346820995 & 0.002700535881606 \\
\hline 25 & -2.988310346820995 & 0.002700535881606 \\
\hline 30 & -2.988310346820995 & 0.002700535881606 \\
\hline
\end{tabular}

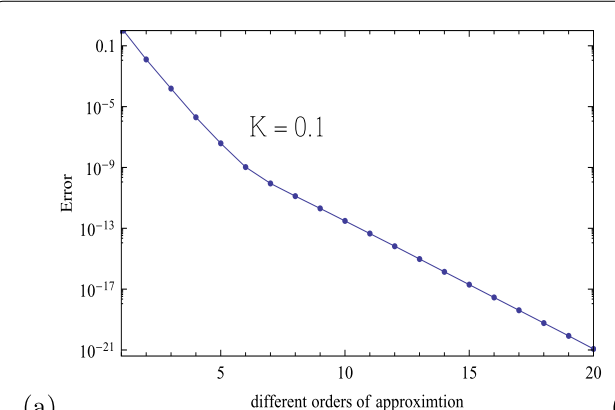

(a)

Figure $1 M a=1, M=1, \Upsilon=0.127013, \operatorname{Pr}=0.2, S=0.2$ and $G r=1$.

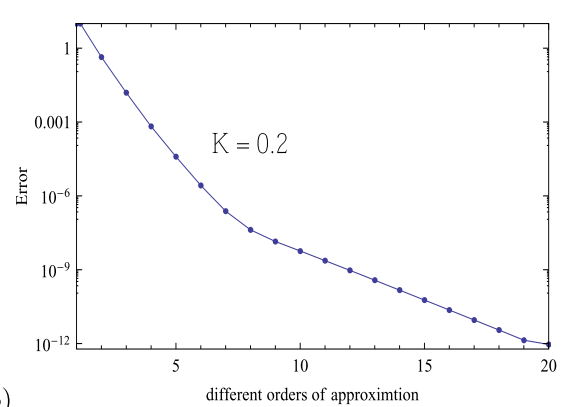

(b)

fixed minimum error of $10^{-40}$ is assigned to the package BVPh2.0. The main advantage of this method is the self-determination of the rate of the homotopy series expansions and solution region; for this purpose the auxiliary parameters $\hbar_{f} \neq 0$ and $\hbar_{\theta} \neq 0$ are included in the solutions (48) and (49). The average residual errors were introduced by Liao [35] to obtain the optimal values of $\hbar_{f}$ and $\hbar_{\theta}$, which are

$$
\begin{aligned}
& \varepsilon_{m}^{f}=\frac{1}{k+1} \sum_{j=0}^{k}\left[\aleph_{f}\left(\sum_{i=0}^{m} F(\eta) \sum_{i=0}^{m} \Theta(\eta)\right)_{\eta=j \delta \eta}\right]^{2} d \eta, \\
& \varepsilon_{m}^{\theta}=\frac{1}{k+1} \sum_{j=0}^{k}\left[\aleph_{\theta}\left(\sum_{i=0}^{m} F(\eta) \sum_{i=0}^{m} \Theta(\eta)\right)_{\eta=j \delta \eta}\right]^{2} d \eta,
\end{aligned}
$$



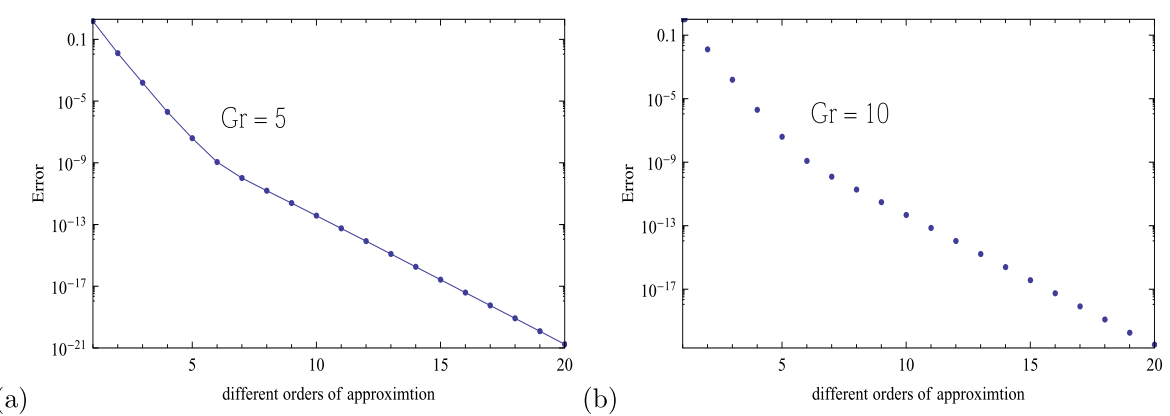

(a)

(b)

Figure $2 M a=1, M=1, \Upsilon=0.127013, \operatorname{Pr}=0.2, S=0.2$ and $K=0.1$.
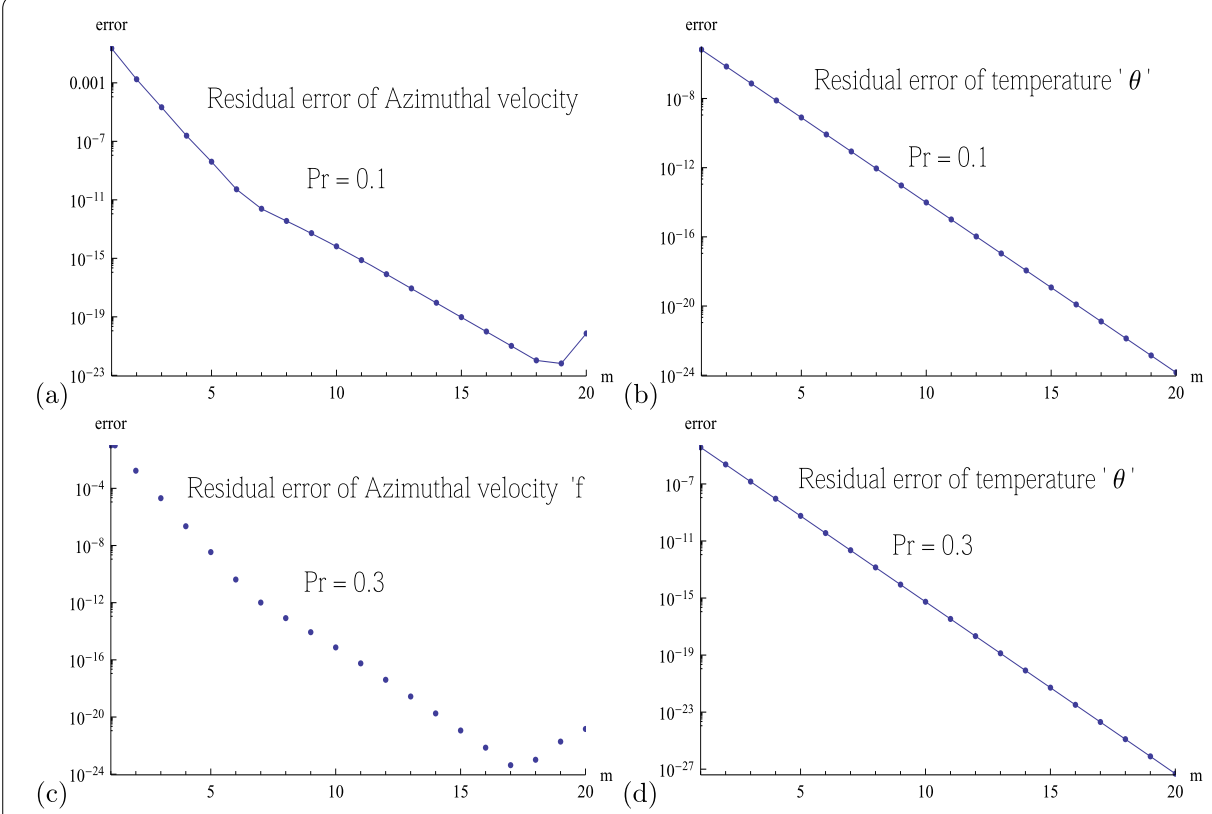

Figure 3 Residual error using 20th-order (HAM) via Mathematica package BVPh2.0 approximation, where $M a=1, M=1, \Upsilon=0.127013, K=0.1, G r=5$ and $S=0.2$.

the total squared residual error was defined by Liao [35] as

$$
\varepsilon_{m}^{t}=\varepsilon_{m}^{f}+\varepsilon_{m}^{\theta}
$$

where $\delta \eta=0.5$ and $k=20$. Zhao [36] introduced the Mathematica package BVPh2.0 for minimizing the total average squared residual error. Considering different cases for varying $K, G r$ and $P r$ we obtained Figure 1 and Figure 2, respectively. In Figure 1, putting $M a=1, M=1, \Upsilon=0.127013, P r=0.2, G r=5, S=0.2$ and varying the second grade parameter $K$ we observe the error for different orders of approximation. Figures 1(a) and 1(b) illustrate the maximum average squared residual error at different orders of approximation. While it is also seen that in Figure 1(a), where for viscoelastic parameter $K=0.1$ it is observed that as the order of approximation is increased the total averaged squared residual errors and averaged squared residual errors are getting smaller, but when $K=0.2$, the error is increased as compared to the case for $K=0.1$ as shown in Figure 1(b). Similarly in 


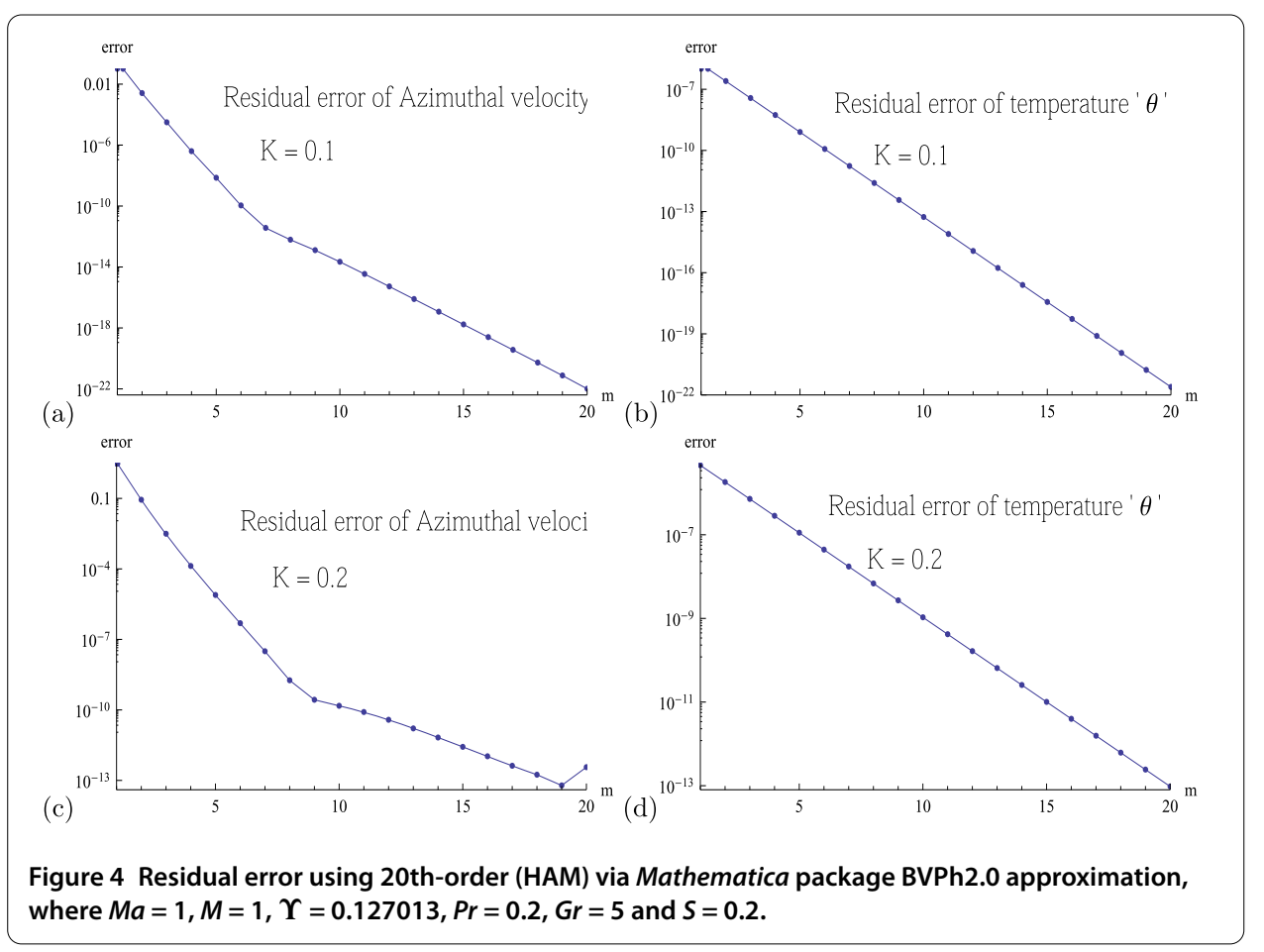

Figure 4 Residual error using 20th-order (HAM) via Mathematica package BVPh2.0 approximation where $M a=1, M=1, \Upsilon=0.127013, P r=0.2, G r=5$ and $S=0.2$.

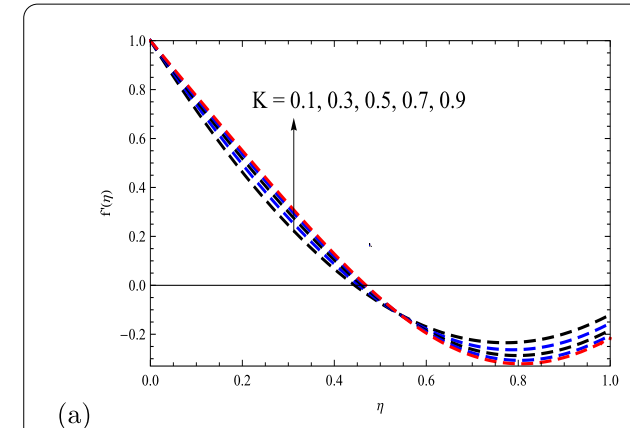

(b)

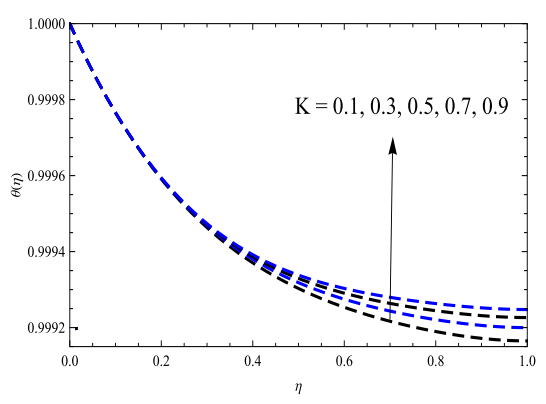

Figure 5 The effect of $K$ on velocity profile and temperature profile with $M a=5, M=1, \Upsilon=0.027013$, $\operatorname{Pr}=0.2, \mathrm{Gr}=5, \mathrm{~S}=0.2$.

cases for $G r=5,10$ it is observed that as the Grashof number is increased the error is increased as shown in Figures 2(a) and 2(b), respectively. Next for the cases for $P r=0.1,0.3$ it is observed that as the Prandtl number is increased the residual error is decreased as shown in Figures 3(a), 3(b), 3(c) and 3(d), respectively. While it is also observed that as the order of approximation increased the residual error decreased shown in Figure 3. Here Figures 4(a), 4(b), 4(c) and 4(d) are about the residual error of azimuthal velocity $f$ and the residual error of the temperature $\theta$. As second grade parameter, $K$ increases both the residual errors of the azimuthal velocity $f$ and the temperature $\theta$, as shown in Figure 4. In addition, Table 1 presents the optimal values of convergence control parameters as well as the minimum values of total averaged squared residual error versus different orders of approximation for $M a=1, M=1, \Upsilon=0.127013, P r=0.2, G r=5, S=0.2, K=0.1$. Table 2 for $M a=1, M=1, \Upsilon=0.127013, P r=0.2, G r=5, S=0.2$ and $K=0.1$ displays the individual average squared residual error at different orders of approximations using the 
self-selection of optimal values by Mathematica package BVPh2.0. Table 3 shows that 15 decimal place accuracy takes place of $f^{\prime \prime}(0)$ and 15 decimal place accuracy takes place of $\theta^{\prime}(0)$ after 20 orders of approximation.

Hence, HAM Mathematica package BVPh2.0 is a choice of selection to the set of local convergence control parameters to get convergent results.

\subsection{Results and discussion}

From second grade fluid (viscoelastic fluid) we obtained nonlinear couple of differential equations (19) and (20) subject to the physical boundary conditions (21) and (22), which are analytically solved by using HAM via the Mathematica package BVPh2.0 for selected non-dimensional values of the film thickness $\beta$, unsteady parameter $S$, Hartmann number $M a$, skin friction, Prandtl number $P r$, thermocapillary number $M$, heat flux, free surface temperature, and Grashof number Gr. Different effects of auxiliary parameters $\hbar_{f}$ and $\hbar_{\theta}$ on $\beta=\Upsilon^{\frac{1}{2}}, f^{\prime \prime}(0), \theta(1)$ and $-\theta^{\prime}(0)$ are shown in Table 4 using a 20th-order HAM approximation when $M a=1, M=1, P r=0.2, G r=5, S=0.2$, and $K=0.1,0.2,0.3$. The effects of the non-dimensional values $K, P r, G r$ and $S$ on $\beta^{2}=\Upsilon, f^{\prime \prime}(0), \theta(1)$ and $-\theta^{\prime}(0)$ are presented in Tables 5-8. For investigation, the effect of various involved physical parameters are studied with the aid of graphs and with tabulated results by means of analytical method HAM.

Based on Table 5, increasing the value of second grade parameter $K$ will reduce the film thickness $\beta^{2}=\Upsilon$ and the heat flux $-\theta^{\prime}(0)$ also decrease, but the skin friction $f^{\prime \prime}(0)$ and the value of free temperature $\theta(1)$ increases for the case $G r=5$, and for $G r=10$ significant impacts in the values of $-\theta^{\prime}(0), \theta(1)$ and $f^{\prime \prime}(0)$ is seen. In Table 6 significant impact is involved in heat flux $-\theta^{\prime}(0)$ and free temperature $\theta(1)$, by increasing the values of Prandtl number $\operatorname{Pr}$ will decrease the film thickness $\beta^{2}=\Upsilon$ and heat flux $-\theta^{\prime}(0)$ while, the skin friction $f^{\prime \prime}(0)$ and free temperature $\theta(1)$ increases for the case $K=0.1$ and for $K=0.3$ similar pattern are investigated in Table 6 . Similarly by increasing the Grashof number $G r$, the film thickness $\beta^{2}=\Upsilon$ and the heat flux $-\theta^{\prime}(0)$ decreases, while free temperature $\theta(1)$

Table 4 Variation of $\beta^{2}=\Upsilon, f^{\prime \prime}(0), \theta(1)$ and $-\theta^{\prime}(0)$ using 20th-order (HAM) via Mathematica package BVPh2.0 approximation when $M a=1, M=1, P r=0.2, G r=5$ and $S=0.2$

\begin{tabular}{llllll}
\hline$\hbar_{\boldsymbol{f}}$ & $\hbar_{\boldsymbol{\theta}}$ & $\boldsymbol{\beta}^{\mathbf{2}}$ & $\boldsymbol{f}^{\prime \prime}(\mathbf{0})$ & $\boldsymbol{\theta}(\mathbf{1})$ & $\boldsymbol{\theta}^{\prime}(\mathbf{0})$ \\
\hline$K=0.1$ & & & & & \\
-0.832780 & -0.941760 & 0.727013 & -3.16449 & 0.977408 & 0.0721367 \\
-0.836000 & -0.857229 & 0.527013 & -3.11339 & 0.983654 & 0.0524063 \\
-0.838367 & -0.795225 & 0.327013 & -3.06291 & 0.989878 & 0.0325884 \\
-0.840192 & -0.717392 & 0.127013 & -3.01303 & 0.996077 & 0.0126844 \\
-0.840993 & -0.617020 & 0.027013 & -2.98831 & 0.999166 & 0.0027005 \\
$K=0.2$ & & & & & \\
-0.720505 & -0.669723 & 0.727013 & -2.98309 & 0.977904 & 0.0721543 \\
-0.72187 & -0.614013 & 0.527013 & -2.93775 & 0.984014 & 0.0524153 \\
-0.72276 & -0.555679 & 0.327013 & -2.89292 & 0.990101 & 0.0325917 \\
-0.723643 & -0.475951 & 0.127013 & -2.84858 & 0.996164 & 0.0126848 \\
-0.724163 & -0.372249 & 0.027013 & -2.82660 & 0.999185 & 0.0027003 \\
$K=0.3$ & & & & & \\
-0.632928 & -0.491987 & 0.727013 & -2.84154 & 0.978332 & 0.0721680 \\
-0.633377 & -0.453117 & 0.527013 & -2.80042 & 0.984325 & 0.0524221 \\
-0.633868 & -0.413418 & 0.327013 & -2.75968 & 0.990294 & 0.0325937 \\
-0.634495 & -0.359594 & 0.127013 & -2.71935 & 0.996239 & 0.0126836 \\
-0.634866 & -0.309759 & 0.027013 & -2.69935 & 0.999201 & 0.0026989 \\
\hline
\end{tabular}


Table 5 Variation of $\beta^{2}=\Upsilon, f^{\prime \prime}(0), \theta(1)$ and $-\theta^{\prime}(0)$ using 20th-order HAM via Mathematica package BVPh2.0 approximation when $M a=1, M=1, \operatorname{Pr}=0.2, S=0.2$ and $K$ is varied

\begin{tabular}{lllll}
\hline $\boldsymbol{K}$ & $\boldsymbol{\beta}^{\mathbf{2}}$ & $\boldsymbol{f}^{\prime \prime}(\mathbf{0})$ & $\boldsymbol{\theta}(\mathbf{1})$ & $\boldsymbol{- \theta}^{\prime} \mathbf{( 0 )}$ \\
\hline$G r=5$ & & & & \\
0.10 & 0.727013 & -3.16449 & 0.977408 & 0.0721367 \\
0.15 & 0.527013 & -3.01960 & 0.983841 & 0.0524111 \\
0.20 & 0.327013 & -2.89292 & 0.990101 & 0.0325917 \\
0.25 & 0.127013 & -2.78049 & 0.996202 & 0.0126846 \\
0.30 & 0.027013 & -2.69935 & 0.999201 & 0.0026989 \\
$G r=10$ & & & & \\
0.10 & 0.727013 & -3.17265 & 0.977385 & 0.0721359 \\
0.15 & 0.527013 & -3.02354 & 0.983833 & 0.0524109 \\
0.20 & 0.327013 & -2.89432 & 0.990099 & 0.0325917 \\
0.25 & 0.127013 & -2.78069 & 0.996202 & 0.0126846 \\
0.30 & 0.027013 & -2.69935 & 0.999201 & 0.0026989 \\
\hline
\end{tabular}

Table 6 Variation of $\beta^{2}=\Upsilon, f^{\prime \prime}(0), \theta(1)$ and $-\theta^{\prime}(0)$ using 20th-order HAM via Mathematica package BVPh2.0 approximation when $M a=1, M=1, G r=5, S=0.2$ and $P r$ is varied

\begin{tabular}{lllll}
\hline $\boldsymbol{P r}$ & $\boldsymbol{\beta}^{\mathbf{2}}$ & $\boldsymbol{f}^{\prime \prime}(\mathbf{0})$ & $\boldsymbol{\theta ( 1 )}$ & $\boldsymbol{\theta}^{\prime}(\mathbf{0})$ \\
\hline$K=0.1$ & & & & \\
0.4 & 0.527013 & -3.11042 & 0.967667 & 0.1042320 \\
0.6 & 0.327013 & -3.05718 & 0.970051 & 0.0970981 \\
0.8 & 0.127013 & -3.00845 & 0.984435 & 0.0505359 \\
1.0 & 0.027013 & -2.98683 & 0.995842 & 0.0134874 \\
$K=0.3$ & & & & \\
0.4 & 0.527013 & -2.79721 & 0.968979 & 0.1042950 \\
0.6 & 0.327013 & -2.75420 & 0.971266 & 0.0971506 \\
0.8 & 0.127013 & -2.71525 & 0.985072 & 0.0505494 \\
1.0 & 0.027013 & -2.69804 & 0.996014 & 0.0134869 \\
\hline
\end{tabular}

Table 7 Variation of $\beta^{2}=\Upsilon, f^{\prime \prime}(0), \theta(1)$ and $-\theta^{\prime}(0)$ using 20th-order HAM via Mathematica package BVPh2.0 approximation when $M a=1, M=1, \operatorname{Pr}=0.2, S=0.2$ and $G r$ is varied

\begin{tabular}{cllll}
\hline $\boldsymbol{G r}$ & $\boldsymbol{\beta}^{\mathbf{2}}$ & $\boldsymbol{f}^{\prime \prime}(\mathbf{0})$ & $\boldsymbol{\theta ( 1 )}$ & $\boldsymbol{\theta}^{\prime}(\mathbf{0})$ \\
\hline$K=0.1$ & & & & \\
1 & 0.727013 & -3.15798 & 0.977426 & 0.0721373 \\
3 & 0.527013 & -3.11168 & 0.983657 & 0.0524064 \\
5 & 0.327013 & -3.06291 & 0.989878 & 0.0325884 \\
10 & 0.127013 & -3.01328 & 0.996077 & 0.0126844 \\
20 & 0.027013 & -2.98834 & 0.999166 & 0.0027005 \\
$K=0.3$ & & & & \\
1 & 0.727013 & -2.83675 & 0.978347 & 0.0721684 \\
3 & 0.527013 & -2.79914 & 0.984328 & 0.0524222 \\
5 & 0.327013 & -2.75968 & 0.990294 & 0.0325937 \\
10 & 0.127013 & -2.71954 & 0.996239 & 0.0126833 \\
20 & 0.027013 & -2.69937 & 0.999201 & 0.0026989 \\
\hline
\end{tabular}

and the skin friction $f^{\prime \prime}(0)$ increases when $K=0.1$, where for the case $K=0.3$, increasing in $G r$ also increases the free temperature $\theta(1)$ and the skin friction $f^{\prime \prime}(0)$, while the film thickness $\beta^{2}=\Upsilon$ and heat flux $-\theta^{\prime}(0)$ decreases as shown in Table 7; significant impact is involved in $f^{\prime \prime}(0)$ and $\theta(1)$. By increasing the stretching parameter $S$ will increase the skin friction $f^{\prime \prime}(0)$, while film thickness $\beta=\Upsilon^{\frac{1}{2}}$ decreases, but swing impact is detectable in both free temperature $\theta(1)$ and heat flux $-\theta^{\prime}(0)$ when $K=0.1$ as shown in Table 8 . 
Table 8 Variation of $\beta^{2}=\Upsilon, f^{\prime \prime}(0), \theta(1)$ and $-\theta^{\prime}(0)$ using 20th-order HAM via Mathematica package BVPh2.0 approximation when $M a=1, M=1, P r=0.2, G r=5$ and $S$ is varied

\begin{tabular}{lllll}
\hline $\boldsymbol{S}$ & $\boldsymbol{\beta}^{\mathbf{2}}$ & $\boldsymbol{f}^{\prime \prime}(\mathbf{0})$ & $\boldsymbol{\theta ( 1 )}$ & $\boldsymbol{- \theta}^{\prime}(\mathbf{0})$ \\
\hline$K=0.1$ & & & & \\
0.2 & 0.727013 & -3.16449 & 0.977408 & 0.0721367 \\
0.3 & 0.527013 & -2.98620 & 0.970255 & 0.0779990 \\
0.4 & 0.327013 & -2.80557 & 0.973148 & 0.0645101 \\
0.5 & 0.127013 & -2.62791 & 0.986181 & 0.0315136 \\
0.6 & 0.027013 & -2.47627 & 0.996330 & 0.0080868 \\
$K=0.3$ & & & & \\
0.2 & 0.727013 & -2.84154 & 0.978332 & 0.0721680 \\
0.3 & 0.527013 & -2.71539 & 0.970797 & 0.0780346 \\
0.4 & 0.327013 & -2.58351 & 0.973421 & 0.0645281 \\
0.5 & 0.127013 & -2.45124 & 0.986266 & 0.0315166 \\
0.6 & 0.027013 & -2.33454 & 0.996345 & 0.0080868 \\
\hline
\end{tabular}
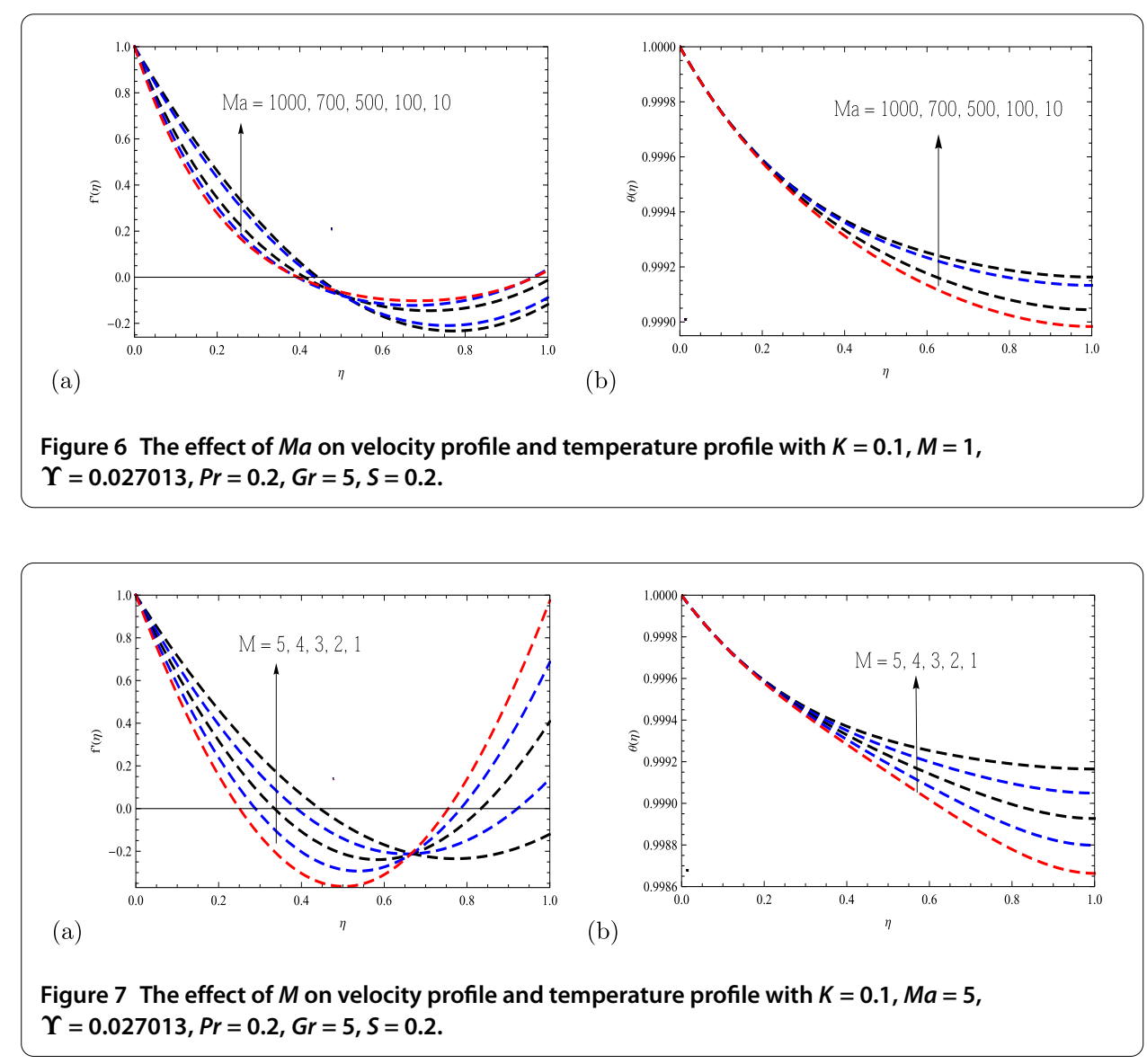

Meanwhile the case when $K=0.3$ has been discussed in Table 8 and a similar behavior is observed as it was seen for $K=0.1$.

Demonstration of the temperature and velocity profiles for electrically conducted hydromagnetics second grade flow under non-isothermal condition over an unsteady stretching sheet is shown in Figures 5-10 when $K, M a, M, \Upsilon, P r$ and $S$ are varying over many values, respectively. By increasing the value of viscoelastic parameter $K$, temperature increases as shown in Figure 5(b), while the flow velocity initially increases and after $\eta=0.52$ it starts decreasing with the increasing of viscoelastic parameter. It means lit- 


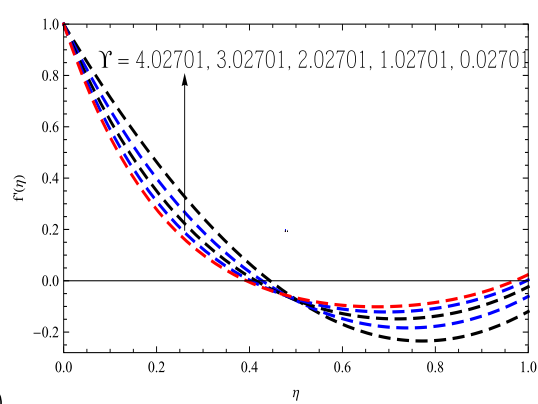

(a)

Figure 8 The effect of $\Upsilon$ on velocity profile and temperature profile with $K=0.1, M=1, M a=5$, $\operatorname{Pr}=0.2, \mathrm{Gr}=5, \mathrm{~S}=0.2$.

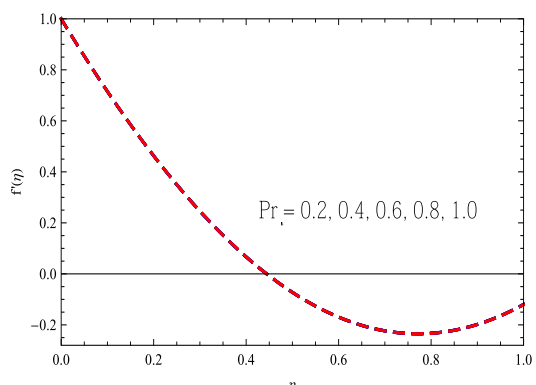

(a)

Figure 9 The effect of $\operatorname{Pr}$ on velocity profile and temperature profile with $K=0.1, M=1, M a=5$, $\Upsilon=0.027013, G r=5, S=0.2$.

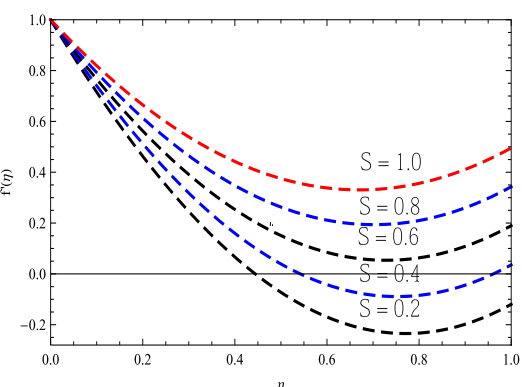

(a)

(b)

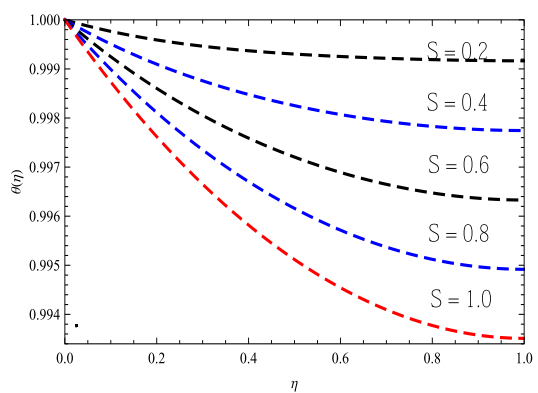

Figure 10 The effect of $S$ on velocity profile and temperature profile with $K=0.1, M=1, M a=5$, $\Upsilon=0.027013, \operatorname{Pr}=0.2, \mathrm{Gr}=5$.

tle swing impact is observed in the velocity profile as shown in Figure 5(a). Figures 6(a) and 6(b) demonstrate the effect of applied transverse magnetic field parameter $M a$, we observed interesting results of the physical problem. As $M a$ increases in Figure 6(a), the flow velocity decreases initially but after $\eta=0.48$ it starts increasing slightly due to the fact that initially applied transverse magnetic field produces a drag in the form of Lorentz force thereby decreasing the magnitude of the velocity. Meanwhile the temperature of the flow increases significantly with the increment in the magnetic field $M a$ as shown in Figure 6(b). By increasing the surface tension gradient $M$ (thermocapillary number), the 
flow velocity decreases initially but after $\eta=0.66$ it starts increasing, that is, the flow turns from slight deceleration to higher velocity and the temperature decreases as shown in Figures 7(a)-7(b), respectively. Increasing the thermocapillary number $M$ leads to higher heat diffusivity on the stretching sheet; thus the Nusselt number $N u_{x}$ is increased, while the flow is cooling down. Reduction of the temperature produces the vibrating force in the fluid molecules. According to the mass conservation law if the force is reduced in the flow direction, then the skin friction $C_{f}$ also decreases. The effect of film thickness $\beta^{2}=\Upsilon$ on the velocity profile and the temperature distribution is shown in Figures 8(a) and 8(b). Thin film flow slightly swings from deceleration to higher velocity, it means that the flow velocity initially decreases up to $\eta=0.48$ and then increases consistently, while the temperature effect uniformly decreases see in Figures 8(a) and 8(b), respectively. The effect of the Prandtl number $\operatorname{Pr}$ (the ratio of momentum diffusivity and thermal diffusivity), on velocity profile and temperature distribution is shown in Figures 9(a) and 9(b). One can see in Figure 9(b) that increasing the Prandtl number $P r$, the heat transfer $-\theta^{\prime}(0)$ slows down and this decrease is seen in the whole domain of fluid, causing the flow to cool. But the flow velocity remains unchanged as the Prandtl number increases as shown in Figure 9(a). Here, it can be seen in Figure 10(a) that the friction and velocity of fluid flow increases by increasing the stretching parameter, $S$. As a result heat flux $\theta^{\prime}(0)$ increases in the boundary layer region, which is compatible with the physical phenomena. Figure 10(b) is plotted to observed the effect of the temperature distribution. Here we see that when the stretching parameter, $S$, is increasing, the temperature consistently decreases.

\section{Concluding remarks}

In this investigation, the effects of Grashof number Gr and Prandtl number $P r$ under the influence of MHD convection in second grade fluid flow over the surface of a stretching sheet with heat transfer is studied. The system of two-dimensional partial differential equations is transformed into a system of ordinary differential equations. The developed nonlinear ordinary differential equations are solved analytically by HAM. The following conclusions are drawn during investigation:

1. It is concluded that as the second grade parameter $K$ increases the flow velocity decreases slightly up to some extent and then increases, it means swing impact is detectable, while temperature consistently increases.

2. It is also concluded that by increasing magnetic parameter $M a$, the thin film flow swings from slight deceleration to higher velocity and temperature is lowered.

3. It is found that increasing the thermocapillary number $M$, the flow velocity form a parabolic profile while temperature is lowered.

4. Moreover, increasing the film thickness $\Upsilon$, the flow swings from lower velocity to higher velocity and temperature is lowered consistently.

5. Furthermore increasing the Prandtl number $P r$, the flow temperature decreases and velocity remains unchanged for fixed values of parameter.

6. It is also investigated that as the magnitude of stretching parameter $S$ rise the velocity increases and the temperature is lowered. 


\section{Funding}

This paper is self-supported by the authors in respect of funding and technically supported by Islamia Collogue University, Khyber Pakhtunkhwa, Peshawar, Pakistan.

\section{Nomenclature}

Regular: $P$, pressure $\left(\mathrm{N} . \mathrm{m}^{-2}\right) P_{0}$, pressure at the stretching sheet $\left(\mathrm{N} . \mathrm{m}^{-2}\right) ; P_{\text {ref }}$, reference pressure $\left(\mathrm{N} . \mathrm{m}^{-2}\right) ; b$, positive constant $\left(\mathrm{s}^{-1}\right) ; t$, time $(\mathrm{s}) ; u, v, x$ and $y$ components of velocity $\left(\mathrm{m} . \mathrm{s}^{-1}\right) ; x, y$, spatial Cartesian coordinates $(\mathrm{m}) ; \operatorname{Pr}$, Prandt number $(v / k) ; B$, magnetic field $\left(\mathrm{k}_{\mathrm{g}} \mathrm{g}^{1 / 2} \cdot \mathrm{m}^{-1 / 2} \cdot \mathrm{s}^{-1}\right)$; $\mathrm{S}$, unsteadiness parameter $(\alpha / b)$; Ma, Hartmann number $\left(L \hat{\sigma} B_{0}^{2} / \cup \rho b\right)$; $h(t)$, liquid film thickness $(m)$; $M$, Thermocapillary number; $T$, temperature $(K) ; T_{0}$, temperature at the stretching sheet $(K)$; $T_{s}$, temperature at the surface of fluid $(K) ; T_{\text {ref }}$, reference temperature $(K) ; L$, characteristic length scale $(m) ; U$, surface velocity $\left(\mathrm{m} \cdot \mathrm{s}^{-1}\right) ; \mathrm{g}$, gravitational acceleration $\left(\mathrm{m} \cdot \mathrm{s}^{-2}\right)$; , thermal expansion coefficient $\left(\mathrm{K}^{-1}\right)$; Subscripts: ref, reference value; $s$, at the surface of fluid; 0 , at the stretching sheet; $G r$, Grashof number; Re, Reynolds number; $P_{s}$, pressure at the surface of

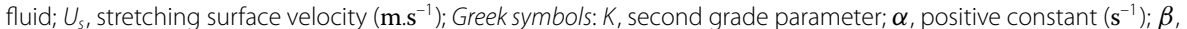
dimensionless film thickness; $\rho$, density $\left(\mathrm{kg} . \mathrm{m}^{-3}\right) ; \delta$, positive constant $\left(\mathrm{K}^{-1}\right) ; \kappa$, thermal diffusivity $\left(\mathrm{W} . \mathrm{m}^{-1} . \mathrm{K}^{-1}\right)$; $\sigma$, surface

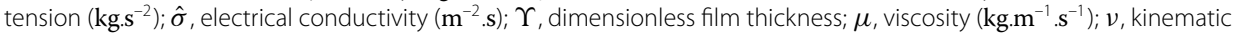
viscosity $\left(\mathrm{m}^{2} \cdot \mathrm{s}^{-1}\right) ; \eta$, similarity variable $\left(\frac{\left(\frac{b}{\nu}\right)^{\frac{1}{2}} \beta^{-1} y}{(1-\alpha t)^{\frac{1}{2}}}\right) ; \delta$, positive fluid property; $\sigma_{0}$, surface tension at sheet $\left(\mathrm{kg} \cdot \mathrm{s}^{-2}\right) ; \hat{\delta}$, characteristic length scale $(\mathrm{m}) ; \theta$, dimensionless temperature; Superscript: $*$, dimensionless variable.

\section{Competing interests}

The authors declare that they have no conflict of interests.

\section{Authors' contributions}

All authors participated in the analysis of the results and manuscript coordination. All authors read and approved the final manuscript.

\section{Author details}

'Department of Basic Sciences and Islamiat, University of Engineering and Technology, Peshawar, Khyber Pakhtoon Khwa, Pakistan. ${ }^{2}$ Department of Mathematics, Islamia College, Peshawar, Khyber Pakhtoon Khwa, Pakistan. ${ }^{3}$ Department of Basic Sciences, Sarhad University, Peshawar, Khyber Pakhtoon Khwa, Pakistan.

\section{Publisher's Note}

Springer Nature remains neutral with regard to jurisdictional claims in published maps and institutional affiliations.

Received: 28 August 2017 Accepted: 27 October 2017 Published online: 07 November 2017

\section{References}

1. Liu, IC, Andersson, HI: Heat transfer in a liquid film on an unsteady stretching sheet. Int. J. Therm. Sci. 47(6), 766-772 (2008)

2. Abbas, Z, Hayat, T, Sajid, M, Asghar, S: Unsteady flow of a second grade fluid film over an unsteady stretching sheet. Math. Comput. Model. 48, 518-526 (2008)

3. Sakiadis, BC: Boundary layer behavior on continuous solid surface I: boundary layer equations for two dimensional and axisymmetric flow. AlChE J. 7, 26-28 (1961)

4. Sakiadis, BC: Boundary layer behaviour on continuous solid surface II: boundary layer on a continuous flat surface. AlChE J. 7, 221-225 (1961)

5. Crane, LJ: Flow past a stretching plate. Z. Angew. Math. Phys. 21, 645-647 (1970)

6. Wang, CY: Liquid film on an unsteady stretching sheet. Q. Appl. Math. 48, 601-610 (1990)

7. Lai, FC, Kulacki, FA: The effect of variable viscosity on convective heat and mass transfer along a vertical surface in saturated porous media. Int. J. Heat Mass Transf. 33, 1028-1031 (1991)

8. Andersson, $\mathrm{HI}$, Aarseth, JB, Dandapat, BS: Heat transfer in a liquid film on an unsteady stretching surface. Int. J. Heat Mass Transf. 43, 69-74 (2000)

9. Liao, SJ: Beyond Perturbation: Introduction to Homotopy Analysis Method, pp. 17-18. Chapman \& Hall, Boca Raton (2004)

10. Wang, C: Analytic solutions for a liquid thin film on an unsteady stretching surface. Heat Mass Transf. 42(8), 759-766 (2006)

11. Wang, C, Pop, I: Analysis of the flow of a power-law fluid film on an unsteady stretching surface by means of homotopy analysis method. J. Non-Newton. Fluid Mech. 138(2), 161-172 (2006)

12. Andersson, $\mathrm{HI}$, Aarseth, JB, Braud, N, Dandapat, BS: Flow of a power-law fluid film on an unsteady stretching surface. J. Non-Newton. Fluid Mech. 62(1), 1-8 (1996)

13. Dandapat, BS, Santra, B, Vajravelu, K: The effects of variable fluid properties and thermocapillarity on the flow of a thin film on an unsteady stretching sheet. Int. J. Heat Mass Transf. 50(5), 991-996 (2007)

14. Chen, $\mathrm{CH}$ : Marangoni effects on forced convection of power-law liquids in a thin film over a stretching surface. Phys. Lett. A 370(1), 51-57 (2007)

15. Abel, MS, Mahesha, N, Tawade, J: Heat transfer in a liquid film over an unsteady stretching surface with viscous dissipation in presence of external magnetic field. Appl. Math. Model. 33(8), 3430-3441 (2009)

16. Noor, NFM, Hashim, I: Thermocapillarity and magnetic field effects in a thin liquid film on an unsteady stretching surface. Int. J. Heat Mass Transf. 53(9), 2044-2051 (2010)

17. Khan, Y, Qingbiao, W, Faraz, N, Yildirim, A: The effect of variable viscosity and thermal conductivity on a thin film flow over a shrinking/stretching sheet. Comput. Math. Appl. 61, 3391-3399 (2011)

18. Hazarika, GC, Konch, J: Effects of variable viscosity and thermal conductivity on magnetohydrodynamic forced convective boundary layer flow past a stretching/shrinking sheet prescribed with variable heat flux in the presence of heat source and constant suction. Int. J. Comput. Appl. 107(1), 50-58 (2014) 
19. Hayat, T, Ahmed, N, Sajid, M, Asghar, S: On the MHD flow of a second grade fluid in a porous channel. Comput. Math. Appl. 54, 407-414 (2007)

20. Abel, MS, Mahesha, N: Heat transfer in MHD viscoelastic fluid flow over a stretching sheet with variable thermal conductivity, non-uniform heat source and radiation. Appl. Math. Model. 32, 1965-1983 (2008)

21. Hayat, T, Shehzad, SA, Qasim, M, Obaidat, S: Flow of a second grade fluid with convective boundary conditions. Therm. Sci. 15, 253-261 (2011)

22. Hussnain, S, Mehmood, A, Ali, A: Three-dimensional channel flow of second grade fluid in rotating frame. Appl. Math. Mech. 33(3), 289-302 (2012)

23. Akinbobola, TE, Okoya, SS: The flow of second grade fluid over a stretching sheet with variable thermal conductivity and viscosity in the presence of heat source/sink. J. Niger. Math. Soc. 34, 331-342 (2015)

24. Gital, AY, Abdulhameed, M, Abdulhamid, BM, Aliyu, MS, Hina, AD: Analytical solution of unsteady flow of a viscoelastic fluid due to an oscillating porous wall. Appl. Math. 5(4), 88-92 (2015)

25. Das, K, Sharma, RP, Sarkar, A: Heat and mass transfer of a second grade magnetohydrodynamic fluid over a convectively heated stretching sheet. J. Comput. Des. Eng. 3(4), 330-336 (2016)

26. Hayat, T, Aziz, A, Muhammad, T, Ahmad, B: On magnetohydrodynamic flow of second grade nanofluid over a nonlinear stretching sheet. J. Magn. Magn. Mater. 408, 99-106 (2016)

27. Dinarvand, S, Doosthoseini, A, Doosthoseini, E, Rashidi, MM: Series solutions for unsteady laminar MHD flow near forward stagnation point of an impulsively rotating and translating sphere in presence of buoyancy forces. Nonlinear Anal., Real World Appl. 11(2), 1159-1169 (2010)

28. Rashidi, MM, Momoniat, E, Rostami, B: Analytic approximate solutions for MHD boundary-layer viscoelastic fluid flow over continuously moving stretching surface by homotopy analysis method with two auxiliary parameters. J. Appl. Math. 2012, Article ID 780415 (2012)

29. Mabood, F, Ibrahim, SM, Rashidi, MM, Shadloo, MS, Lorenzini, G: Non-uniform heat source/sink and Soret effects on MHD non-Darcian convective flow past a stretching sheet in a micropolar fluid with radiation. Int. J. Heat Mass Transf. 93, 674-682 (2016)

30. Qing, J, Bhatti, MM, Abbas, MA, Rashidi, MM, Ali, ME: Entropy generation on MHD Casson nanofluid flow over a porous stretching/shrinking surface. Entropy 18(4), 123-128 (2016)

31. Mabood, F, Shateyi, S, Rashidi, MM, Momoniat, E, Freidoonimehr, N: MHD stagnation point flow heat and mass transfer of nanofluids in porous medium with radiation, viscous dissipation and chemical reaction. Adv. Powder Technol. 27(2), $742-749$ (2016)

32. Abbasbandy, S, Hayat, T, Alsaedi, A, Rashidi, MM: Numerical and analytical solutions for Falkner-Skan flow of MHD Oldroyd-B fluid. Int. J. Numer. Methods Heat Fluid Flow 24(2), 390-401 (2014)

33. Rajagopal, KR, Gupta, AS: An exact solution for the flow of a non-Newtonian fluid past an infinite porous plate. Meccanica 19, 156-160 (1984)

34. Criminale, WO, Ericksen, JL, Filbey, GL: Steady shear flow of non-Newtonian fluid. Arch. Ration. Mech. Anal. 1, 410-417 (1957)

35. Liao, SJ: An optimal homotopy-analysis approach for strongly nonlinear differential equations. Commun. Nonlinear Sci. Numer. Simul. 15(8), 2003-2016 (2010)

36. Zhao, Y: http://numericaltank.sjtu.edu.cn/BVPh2_0.htm (retrieved 30.08.14)

\section{Submit your manuscript to a SpringerOpen ${ }^{\circ}$ journal and benefit from:}

- Convenient online submission

- Rigorous peer review

- Open access: articles freely available online

- High visibility within the field

- Retaining the copyright to your article

Submit your next manuscript at $\gg$ springeropen.com 